\title{
Comparison of aerosol extinction between lidar and SAGE II over Gadanki, a tropical station in India
}

\author{
P. Kulkarni ${ }^{1, *}$ and S. Ramachandran ${ }^{2}$ \\ ${ }^{1}$ Department of Space, National Atmospheric Research Laboratory, Gadanki, Andhra Pradesh, India \\ ${ }^{2}$ Space and Atmospheric Sciences Division, Physical Research Laboratory, Ahmedabad, India \\ * present address: Department of Physics, CMR Institute of Technology, Bangalore, India \\ Correspondence to: P. Kulkarni (padma.narl@gmail.com)
}

Received: 20 September 2014 - Revised: 17 January 2015 - Accepted: 24 February 2015 - Published: 18 March 2015

\begin{abstract}
An extensive comparison of aerosol extinction has been performed using lidar and Stratospheric Aerosol and Gas Experiment (SAGE) II data over Gadanki $\left(13.5^{\circ} \mathrm{N}\right.$, $79.2^{\circ} \mathrm{E}$ ), a tropical station in India, following coincident criteria during volcanically quiescent conditions from 1998 to 2005. The aerosol extinctions derived from lidar are higher than SAGE II during all seasons in the upper troposphere (UT), while in the lower-stratosphere (LS) values are closer. The seasonal mean percent differences between lidar and SAGE II aerosol extinctions are $>100 \%$ in the UT and $<50 \%$ above $25 \mathrm{~km}$. Different techniques (point and limb observations) played the major role in producing the observed differences. SAGE II aerosol extinction in the UT increases as the longitudinal coverage is increased as the spatial aerosol extent increases, while similar extinction values in LS confirm the zonal homogeneity of LS aerosols. The study strongly emphasized that the best meteorological parameters close to the lidar measurement site in terms of space and time and $B_{\mathrm{a}}\left(\mathrm{sr}^{-1}\right)$, the ratio between aerosol backscattering and extinction, are needed for the tropics for a more accurate derivation of aerosol extinction.
\end{abstract}

Keywords. Atmospheric composition and structure (aerosols and particles; instruments and techniques)

\section{Introduction}

The upper troposphere (UT) and lower stratosphere (LS) are regions of highly coupled dynamics and have created major scientific interest due to its particular role in radiative forcing and chemistry-climate coupling. Changes in UTLS aerosol characteristics play an important role in the global and re- gional climate system and the geochemical cycle (Hanson et al., 1994; Borrmann et al., 1997; Solomon et al., 1997). The tropical UT aerosols are important in establishing the characteristics of the stratospheric aerosols, as air enters the stratosphere in the tropics and carries tropospheric aerosol with it (Hamill et al., 1997). There have apparently been no major volcanic eruptions of the magnitude of El Chichón or Mount Pinatubo since 1991. Accordingly, the stratosphere has attained a relatively persistent volcanically quiescent period, in which variations and trends in the "background" stratospheric aerosol can be effectively investigated (Thomason et al., 2008). Recent studies using ground-based lidar and satellite instruments document an increase in stratospheric aerosols of $4-10 \%$ per year from 2000 to 2010 (Vernier et al., 2011b; Hofmann et al., 2009; Nagai et al., 2010; Trickl, 2010). Solomon et al. (2011), using near-global satellite data, reported a negative radiative forcing of about $-0.1 \mathrm{~W} \mathrm{~m}^{-2}$ due to changes in the stratospheric aerosols over the last 10 years starting from 2000 .

The vertically resolved measurements of physical and optical properties of aerosols are of great interest and can be obtained from ground-based lidar, but they are usually restricted both in time and space. Lidar observations of aerosols have been recognized as a valuable complementary source to the information obtained from satellites (Ramaswamy et al., 1995). For both an extensive period of observation and global coverage, satellite payloads are best suited. The Stratospheric Aerosol and Gas Experiment (SAGE) II provided multi-wavelength aerosol extinction coefficient profiles from the mid-troposphere through the stratosphere during October 1984-August 2005. SAGE II aerosol observations have been widely used for providing and studying cli- 
matological behaviour and remain a valuable resource to understand changes in the stratosphere and upper-tropospheric aerosols (e.g. Hitchman et al., 1994; Thomason et al., 1997; Bauman et al., 2003; Thomason and Peter, 2006).

More recently, the spaceborne Cloud-Aerosol Lidar with Orthogonal Polarization (CALIOP) onboard the CALIPSO (Winker et al., 2009) mission is dedicated to the study of clouds and aerosols from the troposphere to the stratosphere since June 2006 and its measurements have provided a wealth of information. In Vernier et al. (2011a), observations using CALIPSO identified the presence of an enhancement in aerosol backscatter closely associated with the Asian monsoonal circulation, and this is termed the Asian tropopause aerosol layer (ATAL). Evidence of ATAL is also observed in SAGE II (Thomason and Vernier, 2013); it is a relatively recent phenomenon and was seen every year during 19992005. However, there was no evidence of ATAL in SAGE II at a date prior to 1998. Such evidence of ATAL and other changes in UTLS aerosol characteristics are vital, and observations using optical instruments (ground-based lidar, in situ balloon measurements) and satellites are essential to track the evolution of UTLS aerosols in various parts of the globe.

To the best of our knowledge,three lidar and SAGE II comparisons have been carried out over the Indian region: (1) at Trivandrum (Parameswaran et al., 1991) during volcanically quiescent conditions, (2) at Ahmedabad after the Mt Pinatubo volcanic eruption (Jayaraman et al., 1995) and (3) at Gadanki (Parameswaran et al., 2010). It is to be noted that, in general, the comparisons between lidar and SAGE II focussed on instrument capabilities and were restricted to a limited number of days in the case of (1) and (2). Parameswaran et al. (1991) reported an agreement that was satisfactory between lidar and SAGE II with large variability in tropospheric extinction. Aerosol extinctions between lidar and SAGE II compared well in the 17-30 km altitude region after the Mt Pinatubo eruption (Jayaraman et al., 1995). The lidar profiles were found to match fairly well with the SAGE II profiles (version 6.20) when the spatial separation between the instruments was in the order of a few hundreds of kilometres (Parameswaran et al., 2010). Stratospheric Processes And their Role in Climate (SPARC) assessment (Thomason and Peter, 2006) stressed the need for more comparisons between lidar and satellite data both at midlatitudes and in the tropics, as there is a lack of statistics on the magnitude of differences between SAGE IImeasured and lidar-derived aerosol extinction values. Thus, the present attempt of an extensive comparison, utilizing an 8-year (1998-2005) data set from SAGE II and lidar over a tropical location during volcanically quiescent conditions, to the best of our knowledge, is the first of its kind.

\section{Data sets and analysis method}

\subsection{SAGE II aerosol extinction data}

The latest version, 7.0, of the SAGE II data set (Damadeo et al., 2013) is used in the present study. SAGE II data were collected during each sunrise (sr) and sunset (ss) event encountered by the satellite as it orbits the Earth. The term event means each measurement made by the SAGE II instrument. The measured data were inverted to obtain profiles of the aerosol extinction coefficient $\beta_{\mathrm{ext}}\left(\mathrm{km}^{-1}\right)$ (Chu et al., 1989). SAGE II-measured $\beta_{\text {ext }}$ with uncertainties were available at $0.385,0.453,0.525$ and $1.02 \mu \mathrm{m}$ at a vertical resolution of $0.5 \mathrm{~km}$. SAGE II $1.02 \mu \mathrm{m}$ extinction profiles have $1 \sigma$ relative uncertainties of about $10 \%$ when extinction exceeds $1.0 \times 10^{-4} \mathrm{~km}^{-1}$. The other three shorter-wavelength extinction profiles have $1 \sigma$ relative uncertainties of $\sim 20 \%$ when extinction exceeds $5 \times 10^{-4} \mathrm{~km}^{-1}$ (Chu et al., 1989). The lower limit for the $\beta_{\text {ext }}$ profile at $1.02 \mu \mathrm{m}$ is near the ground or at the cloud top; the lower-altitude limits for profiles at $0.525,0.453$ and $0.385 \mu \mathrm{m}$ were $6.5,10.5$ and $14.5 \mathrm{~km}$ respectively. However, below the tropopause, due to the presence of clouds especially during the monsoon period, aerosol extinction data were not available over the tropics.

SAGE II aerosol observations have been widely used for providing and studying the climatological behaviour of stratospheric aerosols (e.g. Hitchman et al., 1994; Thomason et al., 1997). Aerosol extinction products in version 7.0 have minor changes within the main aerosol layer and are of excellent quality when compared to previous versions. In particular, aerosol extinction in version 7.0 at $0.525 \mu \mathrm{m}$ is in much better agreement with SAGE III version 4.0 than SAGE II version 6.2 (Damadeo et al., 2013). The SAGE II data product includes National Meteorological Center (NMC) information on the meteorology corresponding to each event. Vertical profiles of temperature, pressure and density from the NMC corresponding to each SAGE II event have been used to derive aerosol extinction from lidar.

\subsection{Coincident criteria}

SAGE II coverage was limited by the Earth Radiation Budget Satellite (ERBS) orbital characteristics, and the sensor takes 15 sunrise and 15 sunset observations on a single day, which are equally spaced in longitude around the globe but vary in latitude by a few degrees. It gives near global coverage over a period of 25-40 days. An appropriate selection of coincident criteria is an essential prerequisite in a comparative study in order to have a sizeable number of data sets. We adopted the coincident criteria prescribed in Antuña et al. (2002). The coincident criteria on the basis of geometry were selected as $\pm 5^{\circ}$ in latitude, $\pm 25^{\circ}$ in longitude and $\pm 24 \mathrm{~h}$ in time with respect to the location of Gadanki and corresponding in time to when the lidar measurements were made. Based on the space-coincident criteria, a total of 209 SAGE II events dur- 
ing 1998-2005 were obtained; when the criterion of time was imposed, only 36 events were found to satisfy. The details of the 36 coincident profiles, such as date, location (latitude, longitude) and range $(\mathrm{km})$, that satisfy the coincident criteria are summarized as a function of season in Table 1. The comparison study includes lidar and SAGE II aerosol extinctions derived in the UT and LS region (10-30 km). These 36 coincident profiles were disaggregated into different seasons and analysed.

\subsection{Lidar extinction data}

Gadanki $\left(13.5^{\circ} \mathrm{N}, 79.2^{\circ} \mathrm{E}\right)$ is a tropical rural site in India located at an altitude of about $375 \mathrm{~m}$ above mean sea level and about $80 \mathrm{~km}$ from the Bay of Bengal coast, in southern India (Fig. 1). To understand atmospheric changes with reference to the monsoon conditions, the aerosol characteristics are classified into four seasons, viz., winter (December-January-February, DJF), premonsoon (MarchApril-May, MAM), monsoon (June-July-August, JJA), and postmonsoon (September-October-November, SON). Lidar measurements over Gadanki started in March 1998, and the data obtained during 1998-2005 are used in the study. The $\mathrm{Nd}$ : YAG $0.532 \mu \mathrm{m}$ lidar at Gadanki has been well calibrated and validated in many studies (e.g. Sunilkumar and Parameswaran, 2005; Kulkarni et al., 2008; Parameswaran et al., 2010). Lidar profiles have a range resolution of $0.3 \mathrm{~km}$ and a time resolution of $250 \mathrm{~s}$. The signal-to-noise ratio of lidar is poor up to the desired reference altitude of about $35 \mathrm{~km}$ at $250 \mathrm{~s}$, especially when cirrus clouds are present. To get a sufficient signal-to-noise ratio in the present study, daily lidar measurements are time-integrated over 4-6h for further analysis. The Klett inversion (Klett, 1985) algorithm is applied to the $0.532 \mu \mathrm{m}$ co-polarized lidar signal to obtain profiles of the aerosol extinction coefficient $\beta_{\mathrm{ext}}\left(\mathrm{km}^{-1}\right)$. Further details on the lidar system and the analysis procedure are provided in Kulkarni et al. (2008).

\subsection{Conversion of aerosol backscatter to extinction}

The total (aerosol and air) backscattering coefficient $\left(\beta_{z}\right)$ using the top-to-bottom inversion algorithm proposed by Klett can be written as

$\beta_{z}=\frac{\exp \left(S-S_{m}\right)}{\frac{1}{\beta_{m}}+2 \int_{z}^{z_{m}} \frac{\exp \left(S-S_{m}\right) \mathrm{d} z}{B_{\mathrm{a}}}}$,

where $S$ and $S_{m}$ are the logarithm of the range-corrected photon counts at any altitude $z$ and the reference altitude $z_{m}$ respectively, $\beta_{m}$ corresponds to the Rayleigh backscattering coefficient at altitude $z_{m}$, and $B_{\mathrm{a}}\left(\mathrm{sr}^{-1}\right)$ is the ratio between aerosol backscattering and extinction coefficients. The Klett inversion algorithm (Eq. 1) includes $\beta_{m}$ and $B_{\mathrm{a}}$ values, which are required a priori. A proper selection of these two parameters is essential to derive aerosol extinction profiles accurately and reduce any additional errors. Further aerosol ex-

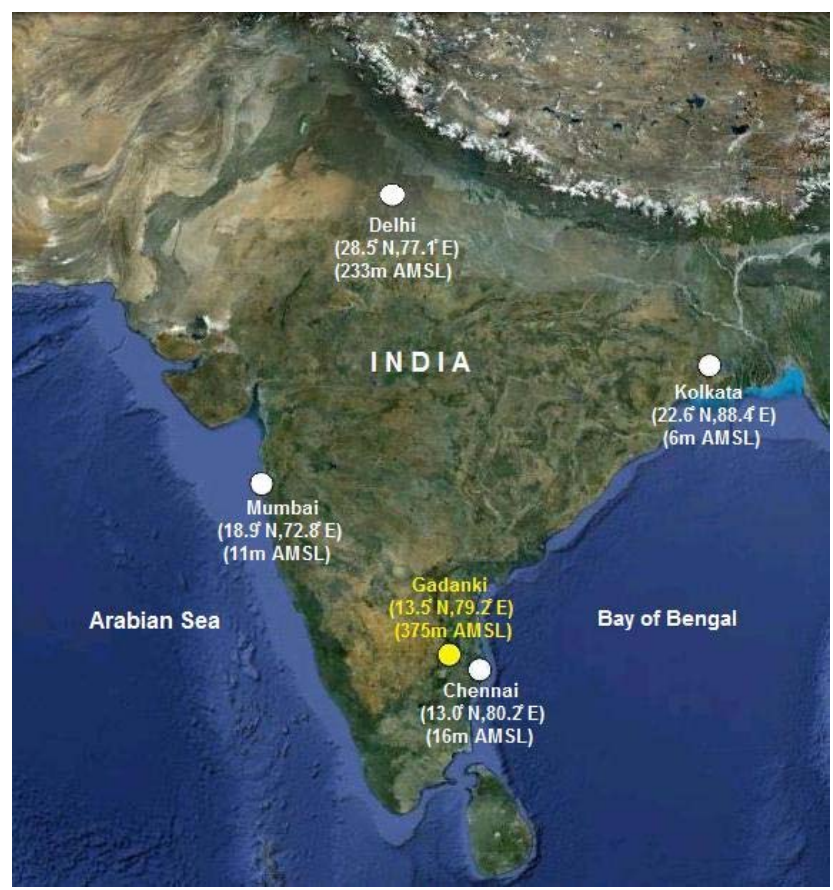

Figure 1. Locations of Gadanki (Google Earth image) where the lidar measurements were made and the four metro cities (Delhi, Kolkata, Mumbai and Chennai) in India.

tinction $\left(\beta_{\text {ext }}\right)$ is obtained using the measured $\beta_{z}$ by assuming a constant $B_{\text {a }}$ value.

$\beta_{m}$ can be determined from the best available meteorological data or approximated using an appropriate standard atmosphere corresponding to the lidar site. In the present study, $\beta_{m}$ is estimated by normalizing molecular density to lidar profiles with two different atmospheric data sets. The data sets correspond to (i) the US Standard Atmosphere (1966) for $15^{\circ} \mathrm{N}$ and (ii) NMC data obtained for each SAGE II coincident event. For a given wavelength $B_{\mathrm{a}}$ depends on the aerosol size distribution, which can be different at different altitudes. Information on $B_{\mathrm{a}}$ values as a function of altitude in the UT and LS does not exist over the tropics. Hence, in the present study we have used $B_{\mathrm{a}}$ values obtained by Jäger and Hofmann (1991) at $0.532 \mu \mathrm{m}$ using lidar and simultaneous balloon-borne optical particle counter data over Garmisch $\left(47.5^{\circ} \mathrm{N}\right)$ during $1980-1987$.

The $B_{\mathrm{a}}$ obtained by Jäger and Hofmann (1991) includes the effects of the 1982 El Chichón volcanic eruption. Ramachandran and Jayaraman (2003) calculated $B_{\mathrm{a}}$ values from Jäger and Hofmann (1991) data corresponding to background conditions (volcanically quiescent; 1980-1982 and 1985-1987, which also includes minor eruptions, but $B_{\mathrm{a}}$ values were not significantly influenced). $B_{\mathrm{a}}$ values were found to be in the range of $0.017-0.022$, with a mean value of about 0.019 (Ramachandran and Jayaraman, 2003). We derived the aerosol extinction coefficients for three $B_{\mathrm{a}}$ values, namely $0.015,0.020$ and 0.025 , which include the measured range of 
Table 1. Details of lidar and SAGE II comparison events during March 1998-August 2005 over Gadanki. SAGE II sunrise (sr) and sunset (ss) events have been chosen based on coincident criteria. See text for details.

\begin{tabular}{|c|c|c|c|c|c|c|}
\hline No of obs & SAGE II & Event & Latitude & Longitude & Range (km) & Lidar \\
\hline \multicolumn{7}{|l|}{ Winter } \\
\hline 1 & 18 Feb 2000 & $\mathrm{sr}$ & $13.35^{\circ} \mathrm{N}$ & $98.98^{\circ} \mathrm{E}$ & 2176 & 17 Feb 2000 \\
\hline 2 & 10 Feb 2001 & ss & $17.88^{\circ} \mathrm{N}$ & $86.99^{\circ} \mathrm{E}$ & 983 & 9 Feb 2001 \\
\hline 3 & 8 Jan 2002 & ss & $16.94^{\circ} \mathrm{N}$ & $82.87^{\circ} \mathrm{E}$ & 553 & 7 Jan 2002 \\
\hline \multirow[t]{2}{*}{4} & 27 Jan 2003 & ss & $13.32^{\circ} \mathrm{N}$ & $84.21^{\circ} \mathrm{E}$ & 551 & 27 Jan 2003 \\
\hline & & & $13.69^{\circ} \mathrm{N}$ & $60.25^{\circ} \mathrm{E}$ & 2085 & \\
\hline 5 & 26 Feb 2004 & $\mathrm{sr}$ & $10.85^{\circ} \mathrm{N}$ & $100.53^{\circ} \mathrm{E}$ & 2364 & 25 Feb 2004 \\
\hline 6 & 27 Feb 2004 & $\mathrm{sr}$ & $11.43^{\circ} \mathrm{N}$ & $76.78^{\circ} \mathrm{E}$ & 350 & 27 Feb 2004 \\
\hline 7 & 7 Dec 2004 & $\mathrm{sr}$ & $17.82^{\circ} \mathrm{N}$ & $85.57^{\circ} \mathrm{E}$ & 847 & 6 Dec 2004 \\
\hline \multirow[t]{2}{*}{8} & 3 Jan 2005 & ss & $10.90^{\circ} \mathrm{N}$ & $86.35^{\circ} \mathrm{E}$ & 837 & 3 Jan 2005 \\
\hline & & & $11.24^{\circ} \mathrm{N}$ & $62.41^{\circ} \mathrm{E}$ & 1864 & \\
\hline \multirow[t]{2}{*}{9} & 4 Jan 2005 & ss & $15.84^{\circ} \mathrm{N}$ & $87.25^{\circ} \mathrm{E}$ & 922 & 4 Jan 2005 \\
\hline & & & $16.16^{\circ} \mathrm{N}$ & $63.31^{\circ} \mathrm{E}$ & 1772 & \\
\hline \multirow[t]{2}{*}{10} & 14 Feb 2005 & $\mathrm{sr}$ & $13.03^{\circ} \mathrm{N}$ & $81.95^{\circ} \mathrm{E}$ & 307 & 14 Feb 2005 \\
\hline & & & $13.64^{\circ} \mathrm{N}$ & $58.28^{\circ} \mathrm{E}$ & 2301 & \\
\hline \multicolumn{7}{|l|}{ Premonsoon } \\
\hline \multirow[t]{2}{*}{11} & 23 Mar 1999 & ss & $12.34^{\circ} \mathrm{N}$ & $97.42^{\circ} \mathrm{E}$ & 2008 & 23 Mar 1999 \\
\hline & & & $11.88^{\circ} \mathrm{N}$ & $73.32^{\circ} \mathrm{E}$ & 671 & \\
\hline \multirow[t]{2}{*}{12} & 17 Mar 2000 & ss & $16.91^{\circ} \mathrm{N}$ & $86.90^{\circ} \mathrm{E}$ & 926 & 17 Mar 2000 \\
\hline & & & $16.47^{\circ} \mathrm{N}$ & $62.84^{\circ} \mathrm{E}$ & 1829 & \\
\hline \multirow{2}{*}{13} & $18 \operatorname{Mar} 2000$ & ss & $9.79^{\circ} \mathrm{N}$ & $85.80^{\circ} \mathrm{E}$ & 833 & $18 \operatorname{Mar} 2000$ \\
\hline & & & $9.48^{\circ} \mathrm{N}$ & $61.72^{\circ} \mathrm{E}$ & 1973 & \\
\hline 14 & 31 Mar 2000 & $\mathrm{sr}$ & $14.00^{\circ} \mathrm{N}$ & $73.54^{\circ} \mathrm{E}$ & 625 & 31 Mar 2000 \\
\hline \multirow[t]{2}{*}{15} & 20 Mar 2002 & $\mathrm{sr}$ & $10.23^{\circ} \mathrm{N}$ & $80.96^{\circ} \mathrm{E}$ & 408 & 20 Mar 2002 \\
\hline & & & $10.72^{\circ} \mathrm{N}$ & $57.01^{\circ} \mathrm{E}$ & 2460 & \\
\hline \multirow[t]{2}{*}{16} & 21 Mar 2002 & $\mathrm{sr}$ & $17.13^{\circ} \mathrm{N}$ & $80.49^{\circ} \mathrm{E}$ & 424 & 21 Mar 2002 \\
\hline & & & $17.55^{\circ} \mathrm{N}$ & $56.45^{\circ} \mathrm{E}$ & 2542 & \\
\hline 17 & 30 May 2002 & $\mathrm{sr}$ & $12.04^{\circ} \mathrm{N}$ & $85.74^{\circ} \mathrm{E}$ & 737 & 29 May 2002 \\
\hline \multirow[t]{2}{*}{18} & 11 Mar 2003 & $\mathrm{sr}$ & $12.52^{\circ} \mathrm{N}$ & $85.78^{\circ} \mathrm{E}$ & 732 & 11 Mar 2003 \\
\hline & & & $13.03^{\circ} \mathrm{N}$ & $61.89^{\circ} \mathrm{E}$ & 1905 & \\
\hline 19 & 19 May 2003 & $\mathrm{sr}$ & $8.28^{\circ} \mathrm{N}$ & $102.53^{\circ} \mathrm{E}$ & 2630 & 19 May 2003 \\
\hline \multirow[t]{3}{*}{20} & 20 May 2003 & $\mathrm{sr}$ & $8.63^{\circ} \mathrm{N}$ & $78.58^{\circ} \mathrm{E}$ & 540 & 20 May 2003 \\
\hline & & & $8.99^{\circ} \mathrm{N}$ & $54.62^{\circ} \mathrm{E}$ & 2749 & \\
\hline & & & $13.47^{\circ} \mathrm{N}$ & $103.23^{\circ} \mathrm{E}$ & 2643 & \\
\hline \multirow[t]{2}{*}{21} & 21 May 2003 & $\mathrm{sr}$ & $13.80^{\circ} \mathrm{N}$ & $79.32^{\circ} \mathrm{E}$ & 36 & 21 May 2003 \\
\hline & & & $14.14^{\circ} \mathrm{N}$ & $55.37^{\circ} \mathrm{E}$ & 2622 & \\
\hline \multirow[t]{2}{*}{22} & 12 Mar 2005 & ss & $9.20^{\circ} \mathrm{N}$ & $84.45^{\circ} \mathrm{E}$ & 746 & 11 Mar 2005 \\
\hline & & & $9.75^{\circ} \mathrm{N}$ & $60.60^{\circ} \mathrm{E}$ & 2087 & \\
\hline 23 & 25 Apr 2005 & $\mathrm{sr}$ & $11.27^{\circ} \mathrm{N}$ & $99.69^{\circ} \mathrm{E}$ & 2267 & 25 Apr 2005 \\
\hline \multirow[t]{2}{*}{24} & 26 Apr 2005 & $\mathrm{sr}$ & $11.65^{\circ} \mathrm{N}$ & $75.85^{\circ} \mathrm{E}$ & 421 & 25 Apr 2005 \\
\hline & & & $16.87^{\circ} \mathrm{N}$ & $101.12^{\circ} \mathrm{E}$ & 2440 & \\
\hline \multicolumn{7}{|l|}{ Monsoon } \\
\hline \multirow[t]{2}{*}{25} & 6 Jun 2001 & $\mathrm{sr}$ & $13.97^{\circ} \mathrm{N}$ & $82.57^{\circ} \mathrm{E}$ & 374 & 6 Jun 2001 \\
\hline & & & $14.29^{\circ} \mathrm{N}$ & $58.42^{\circ} \mathrm{E}$ & 2287 & \\
\hline \multirow[t]{2}{*}{26} & $18 \mathrm{Jul} 2004$ & $\mathrm{sr}$ & $17.06^{\circ} \mathrm{N}$ & $80.08^{\circ} \mathrm{E}$ & 403 & 18 Jul 2004 \\
\hline & & & $17.38^{\circ} \mathrm{N}$ & $56.14^{\circ} \mathrm{E}$ & 2572 & \\
\hline 27 & 4 Jul 2005 & $\mathrm{sr}$ & $11.92^{\circ} \mathrm{N}$ & $100.11^{\circ} \mathrm{E}$ & 2307 & 3 Jul 2005 \\
\hline 28 & 5 Jul 2005 & $\mathrm{sr}$ & $12.24^{\circ} \mathrm{N}$ & $76.18^{\circ} \mathrm{E}$ & 360 & 4 Jul 2005 \\
\hline
\end{tabular}


Table 1. Continued.

\begin{tabular}{|c|c|c|c|c|c|c|}
\hline No of obs & SAGE II & Event & Latitude & Longitude & Range (km) & Lidar \\
\hline \multicolumn{7}{|l|}{ Postmonsoon } \\
\hline 29 & 13 Nov 1998 & $\mathrm{sr}$ & $14.73^{\circ} \mathrm{N}$ & $73.83^{\circ} \mathrm{E}$ & 606 & 13 Nov 1998 \\
\hline \multirow[t]{2}{*}{30} & 9 Nov 1999 & $\mathrm{sr}$ & $14.75^{\circ} \mathrm{N}$ & $84.17^{\circ} \mathrm{E}$ & 564 & 8 Nov 1999 \\
\hline & & & $15.37^{\circ} \mathrm{N}$ & $60.32^{\circ} \mathrm{E}$ & 2087 & \\
\hline \multirow[t]{2}{*}{31} & 12 Sep 2001 & ss & $12.02^{\circ} \mathrm{N}$ & $100.71^{\circ} \mathrm{E}$ & 2372 & 12 Sep 2001 \\
\hline & & & $12.69^{\circ} \mathrm{N}$ & $76.68^{\circ} \mathrm{E}$ & 291 & \\
\hline \multirow[t]{2}{*}{32} & 29 Oct 2001 & $\mathrm{sr}$ & $13.02^{\circ} \mathrm{N}$ & $78.85^{\circ} \mathrm{E}$ & 65 & 29 Oct 2001 \\
\hline & & & $13.62^{\circ} \mathrm{N}$ & $54.96^{\circ} \mathrm{E}$ & 2666 & \\
\hline \multirow[t]{2}{*}{33} & 26 Nov 2001 & ss & $12.37^{\circ} \mathrm{N}$ & $80.82^{\circ} \mathrm{E}$ & 217 & 26 Nov 2001 \\
\hline & & & $12.70^{\circ} \mathrm{N}$ & $56.68^{\circ} \mathrm{E}$ & 2479 & \\
\hline \multirow[t]{3}{*}{34} & 27 Nov 2001 & ss & $16.91^{\circ} \mathrm{N}$ & $102.54^{\circ} \mathrm{E}$ & 2595 & 26 Nov 2001 \\
\hline & & & $17.22^{\circ} \mathrm{N}$ & $78.35^{\circ} \mathrm{E}$ & 420 & \\
\hline & & & $17.54^{\circ} \mathrm{N}$ & $54.18^{\circ} \mathrm{E}$ & 2788 & \\
\hline \multirow[t]{2}{*}{35} & 27 Sep 2004 & $\mathrm{sr}$ & $12.24^{\circ} \mathrm{N}$ & $80.18^{\circ} \mathrm{E}$ & 176 & 27 Sep 2004 \\
\hline & & & $12.72^{\circ} \mathrm{N}$ & $56.46^{\circ} \mathrm{E}$ & 2503 & \\
\hline \multirow[t]{2}{*}{36} & 25 Oct 2004 & ss & $16.63^{\circ} \mathrm{N}$ & $85.45^{\circ} \mathrm{E}$ & 769 & 25 Oct 2004 \\
\hline & & & $17.02^{\circ} \mathrm{N}$ & $61.54^{\circ} \mathrm{E}$ & 1981 & \\
\hline
\end{tabular}

values over Garmisch. The uncertainty in the derived aerosol extinction due to the range of $B_{\mathrm{a}}$ values was found to be about $20-25 \%$ in the $15-30 \mathrm{~km}$ region while it was $<20 \%$ below $15 \mathrm{~km}$. Hence, in the absence of the availability of $B_{\mathrm{a}}$ values for Gadanki, in the present study a $B_{\mathrm{a}}$ of 0.02 has been used, a value appropriate for volcanically quiescent conditions.

Figure $2 \mathrm{a}$ shows the temperature profile from the US Standard Atmosphere model corresponding to $15^{\circ} \mathrm{N}$ and from NMC data for the SAGE II coincident event on 17 March $2000\left(16.91^{\circ} \mathrm{N}, 86.90^{\circ} \mathrm{E}\right)$. US Standard Atmosphere temperatures are higher than the NMC temperature profile in the altitude region of 18 to $28 \mathrm{~km}$. A maximum difference of $7 \mathrm{~K}$ is seen at $22 \mathrm{~km}$, and above $26 \mathrm{~km} \mathrm{a}<2 \mathrm{~K}$ temperature difference is observed. Temperature differences are lower than $2 \mathrm{~K}$ below the tropopause. These two temperature profiles have been used to derive $\beta_{m}$ and $\beta_{\text {ext }}$ from lidar on 17 March 2000 for comparison.

Lidar-derived $\beta_{\text {ext }}$ using the model atmosphere (US Standard Atmosphere, 1966) corresponding to $15^{\circ} \mathrm{N}$ and the NMC meteorological data corresponding to the SAGE II event for a particular coincident event are shown in Fig. 2 b. On 17 March 2000 the sky was clear over Gadanki, with no high-altitude clouds. $\beta_{\text {ext }}$ values are below $10^{-3} \mathrm{~km}^{-1}$ for SAGE II, while lidar values are higher $\left(>10^{-3} \mathrm{~km}^{-1}\right)$. $\beta_{\text {ext }}$ values derived using the US Standard Atmosphere are higher than $\beta_{\text {ext }}$ derived using the NMC temperature profile up to $26 \mathrm{~km}$. As every other parameter in the $\beta_{\text {ext }}$ calculation (Eq. 1) remains the same, except for the temperature and the resultant $\beta_{m}$, this comparison illustrates that the observed shift in $\beta_{\text {ext }}$ is clearly due to the different $\beta_{m}$ values used. $\beta_{m}$ at $33 \mathrm{~km}$ was $1.32 \times 10^{-5} \mathrm{~km}^{-1} \mathrm{sr}^{-1}$ for the NMC temperature profile and $1.38 \times 10^{-5} \mathrm{~km}^{-1} \mathrm{sr}^{-1}$ for US standard atmosphere.
With an attempt to gain further insight into whether the se-

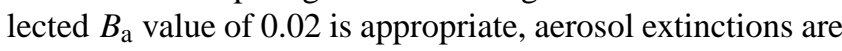
derived for different $B_{\text {a }}$ values (Jäger and Hofmann, 1991) and compared with SAGE II profiles (Fig. 2). Figure $2 \mathrm{~b}$ also includes lidar-derived $\beta_{\text {ext }}$, using NMC for two extreme $B_{\text {a }}$ values (0.0159 and 0.0526) that were obtained during 19801987 (Jäger and Hofmann, 1991). The lidar-derived extinction values at $B_{\mathrm{a}}=0.0526$ are higher in the UT and lower in the LS region when compared to SAGE II. $\beta_{\text {ext }}$ derived using $B_{\mathrm{a}}=0.0159$ is closer to SAGE II between 22 and $34 \mathrm{~km}$. Furthermore, instead of using a constant $B_{\mathrm{a}}$, three different values of $B_{\mathrm{a}}$ are used to examine the sensitivity of aerosol extinction to different values of $B_{\mathrm{a}}$. The values of $B_{\mathrm{a}}$ are allowed to vary as a function of altitude: maximum and minimum values of $B_{\mathrm{a}}$ are 0.0526 and $0.0161(15-20 \mathrm{~km})$, 0.0294 and $0.0159(20-25 \mathrm{~km})$, and 0.0250 and 0.0161 (25$34 \mathrm{~km}$ ) respectively. These values are chosen from Jäger and Hofmann (1991). Aerosol extinction obtained for $B_{\mathrm{a}}$ values that vary with altitude is close to the extinction obtained for $B_{\mathrm{a}}=0.020$ (Fig. 2c). Further aerosol extinction derived for the two sets of $B_{a}$ values - (i) 0.0526 and 0.0204 obtained after the El Chichón volcanic eruption (1982-1984) and (ii) 0.0323 and 0.0159 obtained during volcanically quiescent conditions (1980-1982 and 1985-1987) - is compared with the SAGE II profile obtained on 17 March 2000 (Fig. 2d). A better agrement is seen for the smaller values of 0.0204 and 0.0159 for the LS region. These results suggest that aerosol extinction derived using a $B_{\text {a }}$ value of 0.020 agrees more closely with the SAGE II profile in the LS than in the UT (Fig. 2d). Also the differences in the lidar extinction for different $B_{\mathrm{a}}$ values can occur due to the top-to-bottom inversion algorithm that is being used (Klett, 1985). Hence, in the absence of the availability of $B_{\mathrm{a}}$ values for Gadanki, in the 

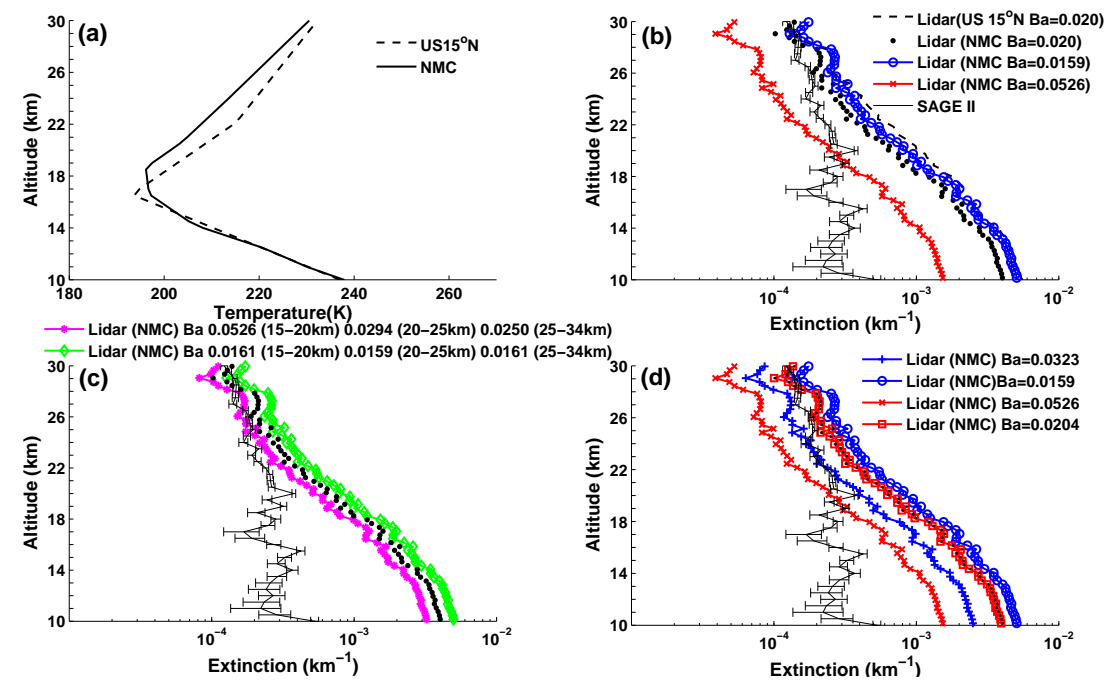

Figure 2. (a) Temperature profiles of US Standard Atmosphere at $15^{\circ} \mathrm{N}$ in comparison with National Meteorological Center (NMC) profile of 17 March $2000\left(16.91^{\circ} \mathrm{N}, 86.90^{\circ} \mathrm{E}\right)$. (b) Lidar-derived $\beta_{\text {ext }}\left(\mathrm{km}^{-1}\right)$ for $B_{\mathrm{a}}=0.020,0.0159,0.0526$ using NMC and $15^{\circ} \mathrm{N} \mathrm{US} \mathrm{Standard}$ Atmosphere with $B_{\mathrm{a}}=0.020$. (c) SAGE II and lidar comparison for different $B_{\mathrm{a}}$ altitude-dependent values using NMC. (d) Aerosol extinction derived using $B_{\mathrm{a}}$ values obtained during volcanically quiescent conditions (1980-1982 and 1985-1987) versus $B_{\mathrm{a}}$ values obtained during El Chichón time frame (1982-1984).

present study a $B_{\text {a }}$ of 0.020 has been used, a value appropriate for volcanically quiescent conditions.

Using the temperature and pressure profiles, molecular density profiles can be computed. Molecular density errors are also the dominant source of error for the aerosol backscattering measurement, at least below $25 \mathrm{~km}$ (Russell et al., 1979), and in turn for $\beta_{\text {ext }}$ values. The present study showed the lidar extinction derived using the NMC temperature profile was closer to the SAGE II extinction values; hence, the NMC temperature profile has been used to derive lidar $\beta_{\text {ext }}$. Also, in contrast to the model US Standard Atmosphere, the temperature profiles from the NMC are near simultaneous. Figure $2 \mathrm{a}, \mathrm{b}$ clearly show that the temperature uncertainties at a higher altitude may have a stronger relative impact on stratospheric aerosol extinctions, thereby stressing the need to opt for the best temperature profile which is close in terms of both space and time to the lidar measurement site and date.

\section{Results and discussion}

\subsection{Comparison of aerosol extinctions and percentage differences between lidar and SAGE II}

The extinction profiles from SAGE II and lidar are plotted seasonally as winter, premonsoon, monsoon and postmonsoon to understand the atmospheric variability. Note that SAGE II-derived $\beta_{\text {ext }}$ from version 7.0 was available at $0.525 \mu \mathrm{m}$ and lidar $\beta_{\text {ext }}$ profiles correspond to $0.532 \mu \mathrm{m}$. Differences, if any, in $\beta_{\text {ext }}$ due to the differences in wavelength will be negligible and are not considered. In Fig. 3, SAGE II profiles are shown as closed circles with solid lines at $0.5 \mathrm{~km}$ resolution and lidar profiles at $0.3 \mathrm{~km}$ resolution are shown as dotted lines. The figure includes only two select comparison profiles; one in which the lidar profile was close to SAGE II (in terms of extinction) and a second in which the differences are quite high. The seasonal mean (including all the profiles) for each season is also given.

The upper troposphere $\beta_{\text {ext }}$ is in the $10^{-2}-10^{-3} \mathrm{~km}^{-1}$ range (Fig. 3), which decreases by about 1-2 orders of magnitude in the lower stratosphere in both lidar and SAGE II profiles. SAGE II vertical profiles were smoother than the lidar aerosol extinction profiles, indicating the possibility of variations in aerosol vertical structure whose scale heights are less than $0.5 \mathrm{~km}$. The comparison between lidar and SAGE II aerosol extinction reveals systematic differences between the two instruments below $25 \mathrm{~km}$, where the aerosol extinctions are higher. This comparison also illustrates that the extinction values are either underestimated by SAGE II and/or overestimated by lidar up to $25 \mathrm{~km}$. There exists a systematic difference in $\beta_{\text {ext }}$ below $25 \mathrm{~km}$ in all the seasons. On a few lidar measurement days, two SAGE II profiles (27 January 2003, 11 March 2003, 18 July 2004, 29 October 2001, 6 June 2001) were found to satisfy the coincident criteria. In such cases all the coincident SAGE II aerosol extinction profiles were plotted in Fig. 3. The two SAGE II profiles show quite a close agreement in the LS (but not in the UT), despite the fact the two profiles are apart by few degrees in latitude and/or longitude. In fact, the difference is more in longitudes, as they differ by $24^{\circ}$; however, the SAGE II profiles are quite close. This is true in other cases, which indicates a zonal uniformity in aerosol characteristics in the LS but not in the UT. The seasonal mean aerosol extinctions are closer in the 16- 

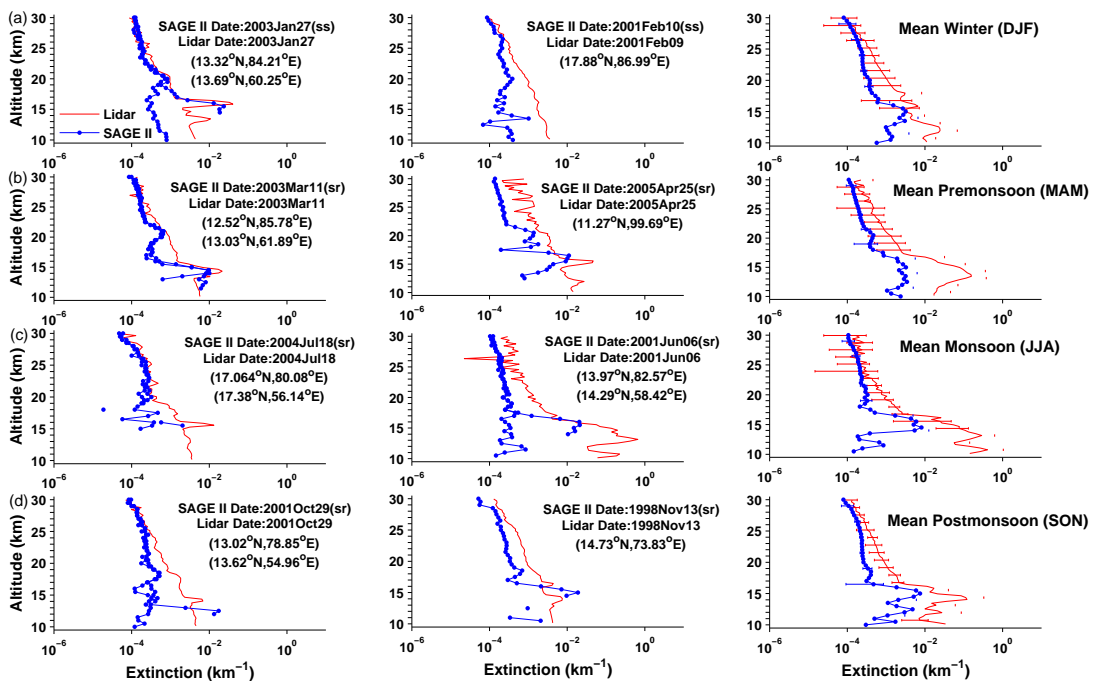

Figure 3. Lidar and SAGE II $\beta_{\text {ext }}\left(\mathrm{km}^{-1}\right)$ aerosol extinction select profiles during March 1998-August 2005 over Gadanki for (a) winter, (b) premonsoon, (c) monsoon and (d) postmonsoon. Seasonal mean $\beta_{\text {ext }}$ and horizontal bars $( \pm 1 \sigma)$ are plotted at the end of each season, including all 36 coincident profiles.

$30 \mathrm{~km}$ altitude range in all seasons, while below $16 \mathrm{~km}$ there exist significant variations, which leads to a larger standard deviation.

The SAGE II instrument was also capable of determining high-altitude cloud cover and its variation. Studies on high cirrus clouds using SAGE II include Wang et al. (1994) and Jensen et al. (1996), to name but two. During the observation period we encountered high-altitude clouds over Gadanki, and these were observed by both lidar and SAGE II. Most of the SAGE II profiles show better agreement around the maximum extinction values measured by lidar (Fig. 3). These maximum extinction values measured by both lidar and SAGE II were found to show good agreement in terms of cirrus cloud heights in the upper-tropospheric region. One of the two SAGE II profiles obtained on 27 January 2003, 11 March 2003, 18 July 2004, 29 October 2001 and 6 June 2001 shows better agreement around the cirrus cloud height (Fig. 3). The other profile might have missed these cirrus clouds as these clouds usually extend horizontally up to $2700 \mathrm{~km}$ and the SAGE II measures at every $24^{\circ}$ of longitude $(\sim 2640 \mathrm{~km})$ along a slowly shifting latitude circle. During the monsoon, aerosol extinction in the UT is higher because of convective activities; this generates the multi-layered highly structured cirrus clouds (Sunilkumar et al., 2010)

To explain the agreement/disagreement between lidar and SAGE II extinctions further, percentage differences in aerosol extinction are obtained for 36 individual profiles. We calculated the differences between each pair of coincident lidar-derived values and those measured by SAGE II, for each pair of profiles obtained from lidar and SAGE II, and refer to them as percentage differences. The ratio of extinc-

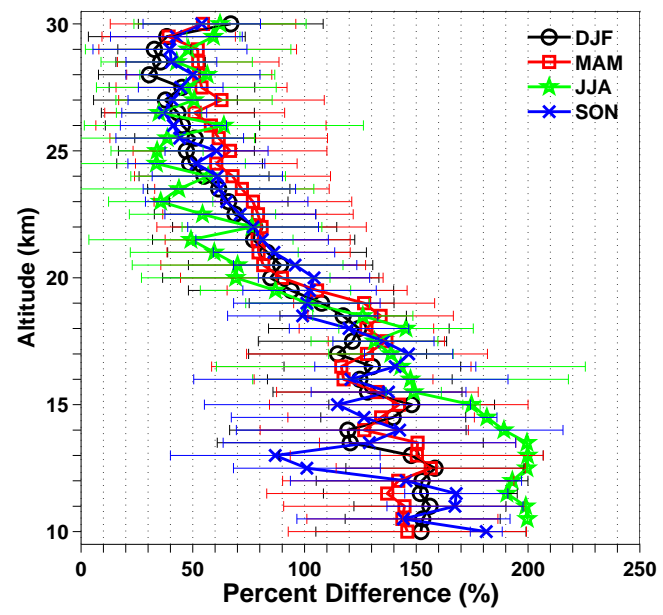

Figure 4. Lidar and SAGE II seasonal mean $\beta_{\text {ext }}\left(\mathrm{km}^{-1}\right)$ percent difference (\%) during March 1998-August 2005.

tion differences at each altitude was divided by the mean of the two extinction values to obtain percent differences.

The largest percent differences occur below the tropopause (Fig. 4), consistent with aerosol extinction. In general, the percent differences decrease as the altitude increases. The percent differences are $>100 \%$ below the tropopause, while above the tropopause and up to $25 \mathrm{~km}$ the percent differences lie in the $50-100 \%$ range. The seasonal mean percent differences (Fig. 4) show that the percent differences can go up to $200 \%$, and the differences are at a maximum during the monsoon because of strong convective activity over the tropics. The percent differences estimated after the Mt Pinatubo eruption were found to exhibit large spatial and temporal variability (Antuña et al., 2003) in the $17-32 \mathrm{~km}$ altitude region. 
The percent difference was found to increase with altitude over Hefei, China $\left(31.9^{\circ} \mathrm{N}, 117.2^{\circ} \mathrm{W}\right)$, and Haute Provence, France $\left(43.9^{\circ} \mathrm{N}, 5.7^{\circ} \mathrm{W}\right)$, while no such increase was seen at Hampton, Virginia $\left(37.1^{\circ} \mathrm{N}, 76.3^{\circ} \mathrm{W}\right)$, Mauna Loa, Hawaii $\left(19.5^{\circ} \mathrm{N}, 155.6^{\circ} \mathrm{W}\right)$ or Camaguey, Cuba $\left(21.4^{\circ} \mathrm{N}, 77.9^{\circ} \mathrm{W}\right)$ (Antuña et al., 2003). The percent difference can be less when there are more aerosols in the atmosphere, such as after a major volcanic eruption. For example, the mean percent differences were $\leq 100 \%$ in the altitudes where the main part of the Pinatubo aerosol cloud was located $(15-25 \mathrm{~km})$ (Antuña et al., 2003).

The ATAL is a relatively recent phenomenon and an important contribution to UT and LS aerosols. Satellite observations from CALIPSO (Vernier et al., 2011a) and SAGE II (Thomason and Vernier, 2013) have revealed an enhancement in aerosols, and this enhancement is called the ATAL. The ATAL exists at the tropopause level associated with the Asian monsoon season in JJA. This ATAL is highly variable in intensity from year to year, with a spatial extent of between roughly 15 and $35^{\circ} \mathrm{N}$ and between about 0 and $150^{\circ} \mathrm{E}$, and vertically from 13 to $18 \mathrm{~km}$. The ATAL is likely to be a primary source of non-volcanic aerosols for the global upper troposphere. In SAGE II data ATAL-like enhancements were not observed in 2005 and in JJA 2003 (Thomason and Vernier, 2013). Further, in this study, since SAGE II data corresponding to a latitude and longitude grid were used, no evidence of ATAL-like enhancement could be seen.

\subsection{Uncertainties in SAGE II and lidar extinctions}

The comparison of results from ground-based and satellite observations is a challenging task, more so when the measurement principle and geometry are different for the two techniques, as in SAGE II and lidar. Thus, as a consequence, such a comparison may not yield exact matches between the two measurements in terms of space and time. In addition, vertical profile observations of aerosols over a tropical region are affected due to the wet climate. The comparison becomes more difficult during volcanically quiescent conditions in the LS when the aerosol extinctions are quite small when compared to the UT (Kulkarni et al., 2008). SAGE II measurements were obtained by looking through a horizontal path of a few hundred kilometres (solar occultation limb viewing) and thus correspond to a horizontally averaged atmosphere, whereas the lidar profiles are obtained vertically and are time-integrated over few hours. The comparison of SAGE II and lidar aerosol extinction profiles over Durban $\left(29.9^{\circ} \mathrm{S}, 31.0^{\circ} \mathrm{E}\right.$; South Africa) (Bencherif et al., 2003) showed discrepancies in the $17-20 \mathrm{~km}$ altitude region during volcanically quiescent conditions. These discrepancies were attributed mainly to the different modes of operation, which is consistent with our results.

Both ground- and space-based measurements of tropospheric and stratospheric aerosols complement each other and have played a major role in providing the necessary in- formation. In particular, lidar and SAGE II have several limitations, uncertainties and initial conditions, as many parameters are derived from the base measurements. In addition, there are spatio-temporal gaps in both the data sets. The main uncertainties between SAGE II and lidar are the differences in the viewing geometry as SAGE II samples the Earth limb tangential to a point on the Earth's surface, with a tangential path length ranging from tens of kilometres at the top of the stratosphere down to about $1200 \mathrm{~km}$ near the Earth's surface. In contrast, lidar measures a single column of the atmosphere, but lidar soundings last from several minutes to hours depending on the number of laser shots selected for the profiling and averaging process.

The other uncertainties in SAGE II- and lidar-derived aerosol extinctions are listed below. There were four sources of error in SAGE II measurement that could have contributed to the total uncertainty in the retrieved vertical profiles (Chu et al., 1989): (1) measurement (instrumental) errors, (2) uncertainty in the calculated Rayleigh profiles caused by the uncertainty in the temperatures, (3) uncertainty in the reference altitude and (4) the uncertainties associated with the removal of other species which have an overlapping contribution in the spectral-wavelength channel. In a sensitivity study Thomason et al. (2008) found that during the low stratospheric aerosol levels from the beginning of 2000 and continuing through the end of its mission in 2005, SAGE II aerosol extinction coefficient profiles remained robust and reliable, and the relative uncertainties associated with measurement noise were larger when compared to higher aerosol loading periods. At $0.525 \mu \mathrm{m}$ the potential bias is less than $10 \%$ through most of the lower stratosphere. At this wavelength, the bias potential is dominated by the uncertainty in the temperature profile data and ozone cross section (Thomason et al., 2008).

The uncertainties in lidar measurements can arise from (1) signal measurement errors, (2) inaccuracy in determining an aerosol-free region for normalization, (3) uncertainty in the calculated Rayleigh profile due to temperature, and (4) using a constant $B_{\mathrm{a}}\left(\mathrm{sr}^{-1}\right)$ value (Russell et al., 1979). Before deriving extinction profiles both SAGE II and lidar instruments require some assumptions on the optical properties of aerosols. A major source of error occurs due to the uncertainty in the molecular profile. We have tried to minimize this by using the temperature profile given by the NMC corresponding to each SAGE II event to determine $\beta_{m}$ for each lidar measurement. Another main source of uncertainty arises due to the constant $B_{\mathrm{a}}$ used to derive the lidar extinction. A constant $B_{\mathrm{a}}$ assumes that the size distribution and composition of the aerosol scatterers do not change with distance from the lidar, and that variations in backscattering from aerosols are due to changes in their number density (Fernald, 1984). The uncertainty in the lidar-derived aerosol extinction due to the use of 0.02 for $B_{\mathrm{a}}$ is estimated to be about $20 \%$ below $15 \mathrm{~km}$, while they were about $20-25 \%$ in the $15-30 \mathrm{~km}$ altitude region. 

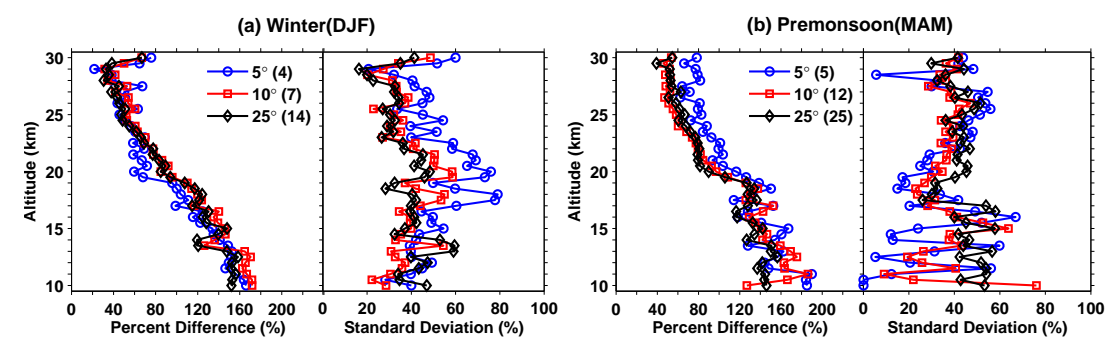

(c) Monsoon(JJA)
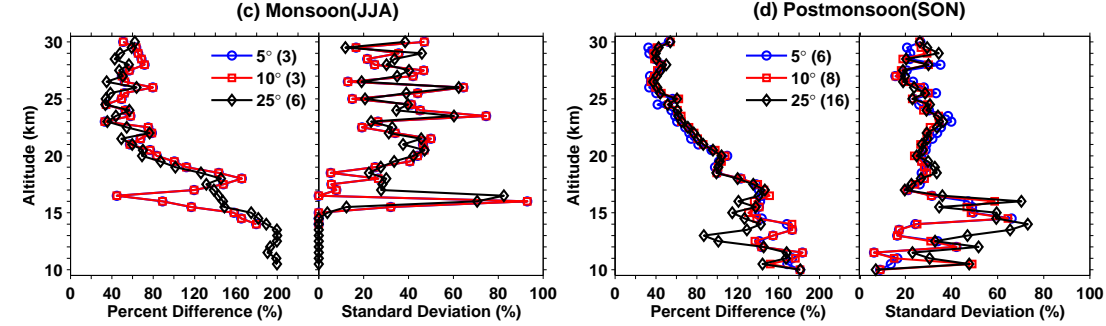

Figure 5. Seasonal mean percentage differences (\%) and corresponding standard deviations (\%) between SAGE II and lidar with respect to different longitudinal bins $\left( \pm 5, \pm 10\right.$, and $\left.\pm 25^{\circ}\right)$ with constant $\pm 5^{\circ}$ latitude during (a) winter, (b) premonsoon, (c) monsoon and (d) postmonsoon.

The largest percentage differences were located below the tropopause (Fig. 4) because of larger variability in the transport of air masses. Even for the measurement where two SAGE II profiles were found to satisfy the coincident criteria (Fig. 3), there were larger variations below the tropopause. Estevan et al. (2008) also showed that upper-troposphere extinction profiles have the biggest disagreement between the SAGE II and lidar, mainly due to the variability of the transport of air masses in the upper troposphere. The zonal homogeneity seen earlier in the current study could be contributing to lesser differences in aerosol characteristics in the LS region. Aerosol variability, technique and a priori assumptions played a major role in producing the observed differences between SAGE II and lidar. In general, due to the abovementioned uncertainties in both profiles, their agreement in the LS can be considered satisfactory.

\subsection{SAGE II and lidar percentage difference and integrated aerosol extinction}

Along with many uncertainties for the comparison as discussed earlier, radial distance could be another source of ambiguity, as the closer the SAGE II event, the finer the comparison with lidar. Earlier comparison studies by Parameswaran et al. (2010) over Gadanki using SAGE II and lidar extinction profiles found fairly good agreement when the radial distance is of the order of a few hundreds of kilometres, while deviation increases with an increase in radial distance. In the present study, to have a sizeable number of data sets, coincident criteria are followed. In order to quantify the general agreement between the extinction profiles from SAGE and lidar, the normalized percentage difference (\%) between the two is estimated for all 36 coincident events during 19982005 in terms of different longitudinal bins $\left( \pm 5, \pm 10, \pm 25^{\circ}\right)$ with fixed latitude $\left( \pm 5^{\circ}\right)$ bins with an aim to determine whether the reduction in longitude affects the comparison. In the lower stratosphere the spatial variability in longitude could be minimal because of efficient mixing in the zonal direction and strong horizontal transport prevailing in the region (Sunilkumar et al., 2011).

Figure 5 shows the percentage difference and corresponding standard deviations at three longitudinal bins for four seasons along with the number profiles used for the comparison. As expected, the percentage difference (SAGE II and lidar) decreases with an increase in altitude, with significant differences confined to the below tropopause region for all seasons. In general, the mean percentage difference is $<50 \%$ in the altitude range above $25 \mathrm{~km}$. However, the percent difference between 18 and $25 \mathrm{~km}$ is $<100 \%$, and in the upper troposphere it is $>100 \%$. The standard deviations (\%) are relatively large $(>40 \%$ ) for the tropospheric region compared to the lower stratosphere. The observed increase in the extinction difference below $17 \mathrm{~km}$ could be due to the influence of cirrus clouds in the UT region as well as their spatial inhomogeneity. Seasonally the postmonsoon and monsoon showed a lower difference between three longitudinal bins in both percent difference and standard deviation compared to other seasons. As the longitude range increases (for \pm 10 and $\pm 25^{\circ}$ ), the number of bins increases, thereby resulting in a slightly higher aerosol extinction. Above the tropopause, the aerosol extinction in the \pm 10 and $\pm 25^{\circ}$ longitudinal bins does not exhibit significant differences throughout the altitude range. However, aerosol extinction obtained within $\pm 5^{\circ}$ difference in longitude with respect to Gadanki shows significant differences above the tropopause, more so during winter and premonsoon (Fig. 5). This comparison illustrates that aerosol extinctions can exhibit differences when the longitudinal ex- 


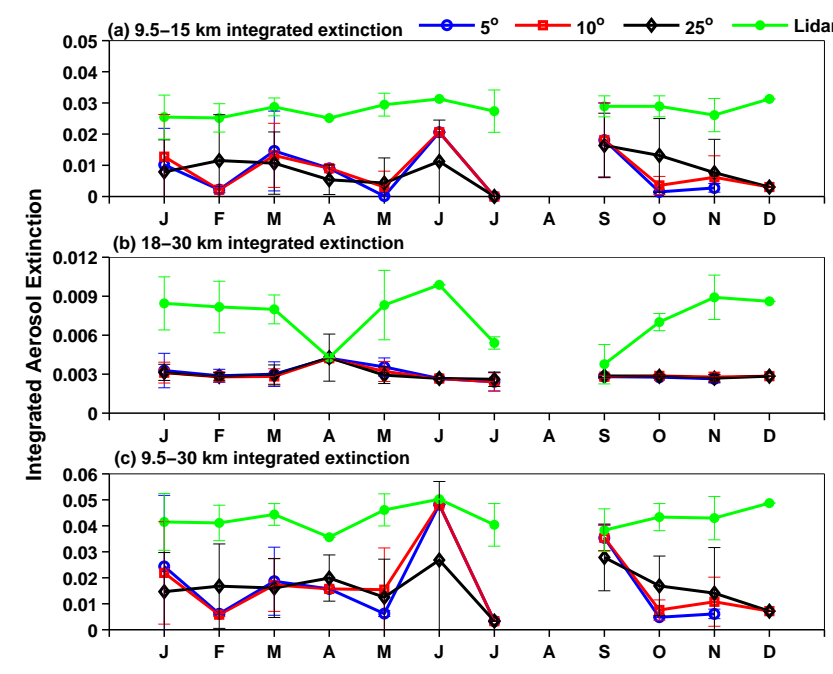

Figure 6. Lidar- and SAGE II-derived monthly mean integrated aerosol extinction during March 1998-August 2005 (for all 36 coincident profiles) over Gadanki for three longitudinal bins $( \pm 5, \pm 10$ and $\pm 25^{\circ}$ ), with constant $\pm 5^{\circ}$ latitude for three altitude regimes ((a) $9.5-15 \mathrm{~km}$, (b) $18-30 \mathrm{~km}$ and (c) $9.5-30 \mathrm{~km}$ ).

tent increases significantly (such as $\pm 25^{\circ}$ ), indicating that spatial variability in aerosol extinction in the zonal direction can occur when the spatial extent is greater.

Figure 6 shows the SAGE II and lidar integrated aerosol extinction in the three altitude regions of (a) UT $(9.5-15 \mathrm{~km})$ (b) LS $(18-30 \mathrm{~km})$ and $(\mathrm{c})$ total $(9.5-30 \mathrm{~km})$ as a function of month during 1998-2005 for all 36 coincident profiles. The SAGE II-derived integrated aerosol extinction is calculated for three longitudinal bins $\left( \pm 5, \pm 10\right.$ and $\left.\pm 25^{\circ}\right)$ with a constant $\pm 5^{\circ}$ latitude with respect to Gadanki $\left(13.5^{\circ} \mathrm{N}\right.$, $79.2^{\circ} \mathrm{E}$ ). The lidar is a monostatic biaxial system and is optically aligned to heights greater than $9 \mathrm{~km}$. Hence, the present study utilizes $9.5 \mathrm{~km}$ as the initial altitude for both SAGE II and lidar integrated aerosol extinction calculation. The UT, LS and total lidar integrated extinctions were in the range of 0.02-0.03, 0.005-0.01 and 0.03-0.05 respectively and are higher in all three altitude regions compared to SAGE II. The lidar integrated extinction of the UT is about 2.5 times higher than that of the LS. The lidar integrated extinctions were found to exhibit seasonal variation in these three altitude regimes. UT extinction is a minimum during winter (DJF), while LS extinction is higher in winter in general. The seasonal pattern of integrated extinction over Gadanki measured using lidar during 2001-2005 (Kulkarni et al., 2008) clearly showed a winter low and a summer high in the UT and more prominently higher values during winter for the LS region.

The SAGE II upper-tropospheric integrated extinction is less than 0.02 (Fig. 6) and is lower than 0.006 in the LS region. Aerosol extinction is higher in June in both lidar and SAGE II. This can be attributed to the increase in the convective activities and a deeper boundary layer over the tropics, which leads to significant increases in aerosol extinction in the UT (Trepte et al., 1994). Aerosol extinction in the UTLS region is dominated by the extinction in the UT, as the LS aerosol extinction is at least 5 times lower. The features of integrated aerosol extinction in the UT and LS regimes are consistent with the profiles obtained in the UT and LS in different seasons. Slight differences between the aerosol integrated extinction measured by SAGE II for three longitudinal bins with a constant latitude have been observed and are attributed to variability in aerosol source strengths, meteorological factors, volcanic influence and uniform seasonal changes (Kent et al., 1998). The SAGE II LS regime (Fig. 6b) does not show clear seasonal variation except the very slight increase during April. The SAGE II LS extinction is more or less similar as the longitudinal bins expand. SAGE II aerosol extinctions in the UT are found to increase as the longitudinal coverage increases, suggesting zonal inhomogeneity, while in the LS aerosol extinction over Gadanki remains the same, confirming the zonal homogeneity of LS aerosols.

\section{Conclusions}

An extensive comparison utilizing an 8-year (1998-2005) data set from SAGE II measured at $0.525 \mu \mathrm{m}$ and lidarderived aerosol extinction at $0.532 \mu \mathrm{m}$ over a tropical location, Gadanki, during volcanically quiescent conditions has been made. The major findings include the following:

1. The aerosol extinctions derived from lidar were found to be higher than the SAGE II values during all seasons in the upper-troposphere region, while in the lower stratosphere the values were closer.

2. The seasonal mean percent differences were $>100 \%$ in the upper troposphere, and between tropopause and $25 \mathrm{~km}$ the percent differences were in the $50-100 \%$ range. The mean percent differences were $<50 \%$ above $25 \mathrm{~km}$.

3. The observed percent differences can mainly be attributed to the different observational techniques, the temperature profile used to determine $\beta_{m}$ and the assumptions made on the optical properties of aerosols $\left(B_{\mathrm{a}}\right)$.

4. Lidar and SAGE II aerosol extinctions agree well when the latitude and longitude of SAGE II profile are closer to the Gadanki site.

5. The lidar integrated extinctions were found to exhibit seasonal variation in the UT, LS and total altitude regimes, and the SAGE II UT integrated extinction is less than 0.02 and is lower than 0.006 in the LS region. Features of the UT and LS regimes are consistent with the profiles obtained in the UT and LS in different seasons. 
6. SAGE II aerosol extinction in the UT increases as the longitudinal coverage increases, indicating spatial inhomogeneity of UT aerosols, while LS extinction values are similar, confirming the zonal homogeneity of LS aerosols.

7. The study highlighted that the best meteorological parameters close to the lidar measurement site in terms of space and time and $B_{\mathrm{a}}\left(\mathrm{sr}^{-1}\right)$, the ratio between aerosol backscattering and extinction, are essential over the tropics for a more accurate derivation of aerosol extinction.

Acknowledgements. The authors are thankful to the technical and scientific staff of the National Atmospheric Research Laboratory (NARL), Gadanki, for their dedicated efforts in conducting the lidar observations. SAGE II spectral aerosol extinction data sets were downloaded from https://eosweb.larc.nasa.gov/project/sage2/ sage2_table.

Topical Editor V. Kotroni thanks two anonymous referees for their help in evaluating this paper.

\section{References}

Antuña, J. C., Robock, A., Stenchikov, G. L., Thomason, L. W., and Barnes, J. E.: Lidar validation of SAGE II aerosol measurements after the 1991 Mount Pinatubo eruption, J. Geophys. Res., 107, 4194, doi:10.1029/2001JD001441, 2002.

Antuña, J. C., Robock, A., Stenchikov, G., Zhou, J., David, C., Barnes, J. E., and Thomason, L. W.: Spatial and temporal variability of the stratospheric aerosol cloud produced by the 1991 Mount Pinatubo eruption, J. Geophys. Res., 108, 4624, doi:10.1029/2003JD003722, 2003.

Bauman, J. J., Russell, P. B., Geller, M. A., and Hamill, P.: A stratospheric aerosol climatology from SAGE II and CLAES measurements: 1. Methodology, J. Geophys. Res., 108, 4382, doi:10.1029/2002JD002992, 2003.

Bencherif, H., Portafaix, T., Baray, J. L., Morel, B., Baldy, S. Leveau, J., Hauchecorne, A., Keckhut, P., Moorgawa, A., Michaelis, M. M., and Diab, R.: Lidar observations of lower stratospheric aerosol over South Africa linked to large scale transport across the southern subtropical barrier, J. Atmos. Sol. Terr. Phy., 65, 707-715, 2003.

Borrmann, S., Solomon, S., Avallone, L., Toohey, D., and Baumgardner, D.: On the occurrence of $\mathrm{ClO}$ in cirrus clouds and volcanic aerosol in the tropopause region, Geophys. Res. Lett., 24, 2011-2014, 1997.

Chu, W. P., McCormick, M. P., Lenoble, J., Brogniez, C., and Pruvost, P.: SAGE II inversion algorithm, J. Geophys. Res., 94, 8339-8351, 1989.

Damadeo, R. P., Zawodny, J. M., Thomason, L. W., and Iyer, N.: SAGE version 7.0 algorithm: application to SAGE II, Atmos. Meas. Tech., 6, 3539-3561, doi:10.5194/amt-6-3539-2013, 2013.

Estevan, R., Antuña, J. C., and Lavorato, M. B.: Stratospheric aerosols measurements at CEILAP, Argentina: Two case studies, Opt. Pura Apl., 41, 101-107, 2008.
Fernald, F. G.: Analysis of atmospheric lidar observations: Some comments, Appl. Optics, 23, 652-653, doi:10.1364/AO.23.000652, 1984.

Hamill, P., Jensen, E. J., Russell, P. B., and Bauman, J. J.: The life cycle of stratospheric aerosol particles, B. Am. Meteorol. Soc., 78, 1395-1410, 1997.

Hanson, D. R., Ravishankara, A. R., and Solomon, S.: Heterogeneous react ions in sulfuric acid aerosols: A framework for model calculations, J. Geophys. Res., 99, 3615-3629, 1994.

Hitchman, M. H., McKay, M., and Trepte, C. R.: A climatology of stratospheric aerosol, J. Geophys. Res., 99, 20689-20700, 1994.

Hofmann, D., Barnes, J., O’Neill, M., Trudeau, M., and Neely, R.: Increase in background stratospheric aerosol observed with lidar at Mauna Loa Observatory and Boulder, Colorado, Geophys. Res. Lett., 36, 1-5, 2009.

Jäger, H. and Hofmann, D. J.: Midlatitude lidar backscatter to mass, area, and extinction conversion model based on in situ aerosol measurements from 1980 to 1987, Appl. Optics, 30, 127-138, 1991.

Jayaraman, A., Ramachandran, S., Acharya, Y. B., and Subbaraya, B. H.: Pinatubo volcanic aerosols layer decay observed at Ahmedabad $\left(23^{\circ} \mathrm{N}\right)$, India, using Nd : YAG backscatter lidar, J. Geophys. Res., 100, 23209-23214, 1995.

Jensen, E. J., Toon, O. B., Selkirk, H. B., Spinhirne, J. D., and Schoeberl, M. R.: On the formation and persistence of subvisible cirrus clouds near the tropical tropopause, J. Geophys. Res., 101, 21361-21375, 1996.

Kent, G. S., Trepte, C. R., and Lucker, P. L.: Long-term stratospheric aerosol and gas experiment I and II measurements of upper tropospheric aerosol characteristics, J. Geophys. Res., 103, 28863-28874, 1998.

Klett, J. D.: Lidar inversion with variable backscatter/extinction ratios, Appl. Optics, 24, 1638-1643, 1985.

Kulkarni, P., Ramachandran, S., Bhavani Kumar, Y., Narayana Rao, D., and Krishnaiah, M.: Features of upper troposphere and lower stratosphere aerosols observed by lidar over Gadanki, a tropical Indian station, J. Geophys. Res., 113, D17207, doi:10.1029/2007JD009411, 2008.

Nagai, T., Liley, B., Sakai, T., Shibata, T., and Uchino, O.: PostPinatubo evolution and subsequent trend of the stratospheric aerosol layer observed by mid-latitude lidars in both hemispheres, SOLA, 6, 69-72, 2010.

Parameswaran, K., Rose, K. O., Krishna Murthy, B. V., Osborn, M. T., and McMaster, L. R.: Comparison of aerosol extinction profiles from Lidar and SAGE II data at a tropical station, J. Geophys. Res., 96, 10861-10866, 1991.

Parameswaran, K., Thampi, B. V., and Sunilkumar, S. V.: Latitudinal dependence of the seasonal variation of particulate extinction in the UTLS over the Indian longitude sector during volcanically quiescent period based on lidar and SAGE-II observations, J. Atmos. Sol. Terr. Phy., 72, 1024-1035, 2010.

Ramachandran, S. and Jayaraman, A.: Balloon-borne study of the upper tropospheric and stratospheric aerosols over a tropical station in India, Tellus, 55B, 820-836, 2003.

Ramaswamy, V., Charlson, R. J., Coakley, J. A., Gras, J. L., Harshvardhan, G. K., McCormick, M. P., Moller, D., Roeckner, E., Stowe, L. L., and Taylor, J.: What are the anticipated and observed meteorological and climatic responses to aerosol forcing, 
in: Aerosol forcing of climate, edited by: Charslon, R. J. and Heintzenberg, J., 386-399, John Wiley, 1995.

Russell, P. B., Swissler, T. J., and McCormick, M. P.: Methodology for error analysis and simulation of lidar aerosol measurements, Appl. Optics, 18, 3783-3797, 1979.

Solomon, S., Borrmann, S., Garcia, R. R., Portmann, R., Thomason, L., Poole, L. R., Winker, D., and McCormick, M. P.: Heterogeneous chlorine chemistry in the tropopause region, J. Geophys. Res., 102, 21411-21429, 1997.

Solomon, S., Daniel, J. S., Neely III, R. R., Vernier, J.-P., Dutton, E. G., and Thomason, L. W.: The persistently variable background stratospheric aerosol layer and global climate change, Science, 333, 866-870, 2011.

Sunilkumar, S. V. and Parameswaran, K.: Temperature dependence of tropical cirrus properties and radiative effects, J. Geophys. Res., 110, D13205, doi:10.1029/2004JD005426, 2005.

Sunilkumar, S. V., Parameswaran, K., Rajeev, K., Krishna Murthy, B. V., Meenu, S., Mehta, S. K., and Babu, A.: Semitransparent cirrus clouds in the Tropical Tropopause Layer during two contrasting seasons, J. Atmos. Sol Terr. Phy., 72, 745-762, doi:10.1016/j.jastp.2010.03.020, 2010.

Sunilkumar, S. V., Parameswaran, K., Thampi, B. V., and Ramkumar, G.: Variability in background stratospheric aerosols over the tropics and its association with atmospheric dynamics, J. Geophys. Res., 116, D13204, doi:10.1029/2010JD015213, 2011.

Thomason, L. W. and Peter, T. (Eds.): Assessment of Stratospheric Aerosol Properties (ASAP), SPARC Report No. 4, WCRP124, WMO/TD-No. 1295, February, available at: http://www. sparc-climate.org/ (last access: 16 March 2015), 2006.

Thomason, L. W. and Vernier, J.-P.: Improved SAGE II cloud/aerosol categorization and observations of the Asian tropopause aerosol layer: 1989-2005, Atmos. Chem. Phys., 13, 4605-4616, doi:10.5194/acp-13-4605-2013, 2013.
Thomason, L. W., Poole, L. R., and Deshler, T.: A global climatology of stratospheric aerosol surface area density deduced from Stratospheric Aerosol and Gas Experiment II measurements: 1984-1994, J. Geophys. Res., 102, 8967-8976, 1997.

Thomason, L. W., Burton, S. P., Luo, B.-P., and Peter, T.: SAGE II measurements of stratospheric aerosol properties at non-volcanic levels, Atmos. Chem. Phys., 8, 983-995, doi:10.5194/acp-8-9832008, 2008.

Trepte, C. R., Thomason, L. W., and Kent, G. S.: Banded structures in stratospheric aerosols distributions, Geophys. Res. Lett., 21, 2397-2400, 1994.

Trickl, T.: 33 years of Stratopsheric Aerosol Measurements at Garmisch-Partenkirchen (1976-2010), 465-468, St.-Petersburg, Russia, 2010.

US Standard Atmosphere Supplements: NASA, US Government Printing Office, Washington D.C., 289 pp., USA, 1966.

Vernier, J.-P., Thomason, L. W., and Kar, J.: CALIPSO detection of an Asian tropopause aerosol 15 layer, Geophys. Res. Lett., 38, L07804, doi:10.1029/2010GL046614, 2011 a.

Vernier, J.-P., Thomason, L. W., Pommereau, J.-P., Bourassa, A., Pelon, J., Garnier, A., Hauchecorne, A., Blanot, L., Trepte, C., Degenstein, D., and Vargas, F.: Major influence of tropical volcanic eruptions on the stratospheric aerosol layer during the last decade, Geophys. Res. Lett., 38, L12807, doi:10.1029/2011GL047563, 2011 b.

Wang, P.-H., McCormick, M. P., Poole, L. R., Chu, W. P., Yue, G. K., Kent, G. S., and Skeens, K. M.: Tropical high cloud characteristics derived from SAGE II extinction measurements, Atmos. Res., 34, 53-83, 1994.

Winker, D. M., Vaughan, M. A., Omar, A., Hu, Y., Powell, K. A., Liu, Z., Hunt, W. H., and Young, S. A.: Overview of the CALIPSO mission and CALIOP data processing algorithms, J. Atmos. Ocean. Tech., 26, 2310-2323, doi:10.1175/2009JTECHA1281.1, 2009. 